\title{
Information Flow Model of Human Extravehicular Activity Operations
}

\author{
Matthew J. Miller \\ Georgia Institute of Technology \\ 270 Ferst Drive, Room 416 \\ Atlanta, GA 30332 \\ 9126746722 \\ mmiller@gatech.edu
}

\author{
Kerry M. McGuire \\ NASA Johnson Space Center \\ Mail Code: SF3 \\ 2101 NASA Parkway \\ Houston, TX 77058 \\ 2814830786 \\ kerry.m.mcguire@nasa.gov
}

\author{
Karen M. Feigh \\ Georgia Institute of Technology \\ 270 Ferst Drive, Room 419 \\ Atlanta, GA 30332 \\ 4043857686 \\ karen.feigh@gatech.edu
}

\begin{abstract}
Future human spaceflight missions will face the complex challenge of performing human extravehicular activity (EVA) beyond the low Earth orbit (LEO) environment. Astronauts will become increasingly isolated from Earth-based mission support and thus will rely heavily on their own decision-making capabilities and onboard tools to accomplish proposed EVA mission objectives. To better address time delay communication issues, EVA characters, e.g. flight controllers, astronauts, etc., and their respective work practices and roles need to be better characterized and understood. This paper presents the results of a study examining the EVA work domain and the personnel that operate within it. The goal is to characterize current and historical roles of ground support, intravehicular (IV) crew and $E V$ crew, their communication patterns and information needs. This work provides a description of EVA operations and identifies issues to be used as a basis for future investigation.
\end{abstract}

\section{TABLE OF CONTENTS}

1. INTRODUCTION .1

2. BACKGROUND ..............................................2

3. METHODS AND MATERIALS ...........................3

4. Human EXTRAVEHICUlaR ACTIVITY .............4

5. EVA INFORMATION FLOW MODEL ..................6

6. Apollo 16 EVA 4 Communication

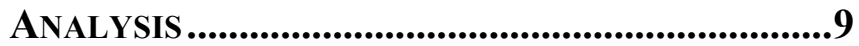

7. DISCUSSION.......................................................13

8. Conclusions ANd Future WORK ...............14

9. ACKNOWLEDGEMENTS ....................................14

REFERENCES..................................................14

BIOGRAPHY ........................................................15

\section{INTRODUCTION}

The NASA human spaceflight program has successfully completed well over 1326 hours of extravehicular activity (EVA) throughout its 50 year history [1]. Thanks to the incremental developments made throughout the Gemini, Apollo, Skylab, Shuttle, and International Space Station (ISS) programs, EVAs have become one of NASA's most iconic and essential component of human spaceflight, demonstrating a range of capabilities including hardware assembly, maintenance, and repair as well as scientific support [2]. For the purposes of this study, an EVA is defined as "any space operation or activity performed outside the protective environment of a spacecraft

978-1-4799-5380-6/15/\$31.00 (C2015 IEEE therefore requiring supplemental or independent life support equipment for the astronaut" [3], pg. 5. The vast majority of EVAs conducted to date have all occurred in a region above Earth ( 100 to $1000 \mathrm{~km})$ known as Low Earth Orbit (LEO). The Apollo EVAs serve as the only precedent for EVAs beyond LEO, yet even these EVAs operated within the Earth-Moon system. A universal characteristic inherent among all performed EVAs is the absences of delayed communication linkages between crew and mission control due to light-time delay. Lighttime delay is associated with the vast distances the communication relays must travel to reach mission control located on Earth. Table I summarizes the one way time-delay for transmissions sent between Earth and various destinations currently under examination for future exploration missions.

Table I. Potential Future Human EVA Environments

\begin{tabular}{|c|c|c|c|c|}
\hline \multirow[t]{2}{*}{ Destination } & \multirow[t]{2}{*}{ Lunar } & NEOs & \multicolumn{2}{|c|}{ Mars } \\
\hline & & Lunar DRO & Close & Opposition \\
\hline $\begin{array}{l}\text { Distance from } \\
\text { Earth, km }\end{array}$ & $3.84 \mathrm{E}+05$ & Variable & $5.57 \mathrm{E}+07$ & $4.01 \mathrm{E}+08$ \\
\hline $\begin{array}{l}\text { One-Way Time } \\
\text { Delay, s (min) }\end{array}$ & 1.3 & Variable & $\begin{array}{l}185.8 \\
(3.1)\end{array}$ & $\begin{array}{l}1338.6 \\
(22.3)\end{array}$ \\
\hline $\begin{array}{c}\text { Mission } \\
\text { Duration, days }\end{array}$ & Variable & $20-30$ & 895 & -950 \\
\hline Ref. & [4] & [5], [6] & & 4] \\
\hline
\end{tabular}

Central to the theme of this study and future works is to better understand the current EVA work domain with the eventual goal of understanding EVAs in the context of deep space, communication time-delayed missions. More specifically, how will the paradigm between mission control center (MCC) and onboard crewmembers have to change to ensure EVA mission success without real-time communication? Current EVA operations leverage 50 years of EVA experience operating with the real-time communication support capability by MCC, with the exception of periodic loss of signal events.

\section{Goals of this Investigation}

The purpose of this study is to identify the primary and secondary operators involved in conducting an EVA in present-day operations. The goal is to characterize current and roles and responsibilities of these operators, and to 
examine their communication patterns and information needs. This work provides a current day perspective of EVA operations and identifies issues to be used as a basis for future investigation. A communication link analysis of an historical EVA is also shown to provide a synthesized view of actual flight audio during an EVA. Apollo 16 EVA 4 was selected as a case study because it serves as the only EVA conducted beyond LEO that was not affiliated with operating directly on the moon's surface. This operational environment is analogous to the future asteroid redirect missions currently being planned by NASA [5].

The rest of the paper is organized as follows. The literature review is outlined in Section 2, followed by the discussion of the research methods in Section 3. Section 4 provides an EVA description. The EVA information flow model and communication analysis is presented in Section 5 and 6 , respectively. A discussion of the results and study limitations is located in Sections 7 and conclusions along with proposed future work are discussed in Section 8.

\section{BACKGROUND}

EVAs have been a topic of study from a variety of perspectives ranging from procedural timeline development [7], tool development [8], and human health and performance [9]. The majority of studies have focused solely on evaluations of either the EVA crewmembers or MCC. However, the existing literature lacks an examination of the interactions between MCC and crewmembers during real-time operations.

Previous studies have examined the MCC to understand how MCC flight controllers and support staff support real-time human spaceflight activities [10], [11]. The MCC is divided among a set of console positions and primarily communicates via a set of voice communication loops (see Ref. [10] for a description of MCC structure and voice loops). MCC studies to-date have not specifically examined the EVA domain. This study contributes to this body of knowledge by focusing on the specific set of voice loops and console positions within MCC known as the EVA front control room (FCR) console and EVA multipurpose support room (MPSR) console positions.

Crewmember focused research includes time and motion studies [12], [13] and evaluations of task efficiency [14], [15]. In particular, Ney and Looper, by examining task time-to-completion, revealed that current ISS EVAs exhibit a level of efficiency that, while adequate for ISS mission objectives, is undesirably low for future human space operations due to the increased constraints on available resources. Building upon the EVA efficiency work, Marquez (2010) integrated an augmented classification of EVA tasks with a comparison of planned versus as-run timelines. Results indicated specific areas within an EVA timeline that demanded more time and areas of decreased efficiency such as support equipment setup. However, no evaluation or conclusions were made regarding MCC support activities or how MCC support integrated with crewmember activities.

The work that has focused on the interactions of MCC and crewmembers, particularly within a time-delayed environment, exists in analog simulation. There are numerous analog sites where field-testing of hardware and spaceflight operations occurs such as NASA Extreme Environment Mission Operations (NEEMO) and Desert Research and Technology Studies (D/RATS). Recent lessons learned from these analog studies indicate the complimentary nature of having both voice and text capability for crew and MCC communication. In the presence of 50-second communication latency, MCC and EVA crewmembers demonstrated they could operate and meet their mission objectives, if the EVA timeline was constructed to accommodate the round-trip communication delay with MCC. However, when unexpected situations were simulated, communications broke down for both 5 and 10-minute latencies [16]. There is a demonstrated need to better understand EVA operations within this time-delayed environment and to assess the potential impacts of crew training and technological support.

Along with field-analogs, virtual simulations have also been conducted at NASA JSC though the RATS 2012 campaign [17] and the Autonomous Mission Operations (AMO) study [18]. Both of these studies employed a series of virtual reality simulation environments to mimic deep space operations. RATS 2012 reiterated the importance of having a dedicated intravehicular activity (IVA) crewmember to handle communications with ground communication, similar to how both Shuttle and ISS EVAs operated. However, this study, along with the previous field-analog simulations, lacked an examination of the information needs, communication patterns, and work practices of the EVA operators to explain the reasons for the observed performance in operations.

While not specifically examining EVA operations, the AMO study, conducted at the Deep Space Habitat at JSC, provides some insight to the possible technological impacts related to mitigating time-delay impacts from both the MCC and crew perspective. This study examined a baseline and mitigation configuration to experimentally investigate whether different technology aides could mitigate some of the challenges caused by time-delay. Workload and coordination difficulty between the ground and flight crew were shown to increase with time delay, but to a lesser extent when mitigation tools where implemented. However, ground crew workload increased, regardless of configuration, with time delay. The same tools that were attributed by the participants to reduce their workload, acted to both reduce and increase workload for the ground crew [18]. The results of this study indicated that there is a place for advanced 
technology in the time-delayed arena but further work is needed to develop these tools and to assess their impact, especially if this sort of technology is added to support the EVA work domain.

While there is much to be learned from $50+$ years of human spaceflight EVA, there is a growing interest for more advanced human-system technology development for a sustained human presence beyond LEO. Recently published literature outlines the need for new systems to support humans in a variety of roles, which include mobility, data acquisition, information technology, autonomous science and assembly, and decision-making [19]. NASA research efforts have already identified numerous challenges when operating in a communicationdelayed environment such as: reduced crew situation awareness, wasted crew time, and an impaired ability to transfer relevant information between flight crew and mission control and vice versa [20]. To overcome the presented challenges of operating in a communicationdelayed environment, understanding the communication dynamics between operators as well as technological implications are key. This study begins to address the aforementioned considerations by establishing the current operational environment in which crewmembers and MCC interact during EVA.

\section{Methods AND Materials}

This study consists of two complimentary efforts. The first being the development of an information flow model of the current EVA work domain, and the second being a communication analysis of the Apollo 16 EVA 4 air-toground voice communication transcript. The information flow model describes how the work is distributed among the EVA operators and how those operators communicate with each other. There is a need to detail current EVA operations in order to incrementally work towards overcoming the challenges within a time-delayed environment. The communication analysis provides some historical context by describing the communication pathways and the frequencies of those pathways as well as the content of communication between the EVA operators for the only EVA performed beyond LEO that was not related to moon surface operations. Again, there is need to leverage historical examples to provide a reference point for future work in EVA operations studies.

\section{Information Flow Model}

An information flow model is a component within a larger research framework known as contextual inquiry (see Ref. [21] for a description of contextual inquiry). Previous studies have implemented contextual inquiry models to examine work domains such as airline operations [22]. The information flow model was completed by conducting a qualitative assessment of the resources available within the EVA community at JSC.
Various sources of data at NASA JSC were leveraged which included relevant stakeholders, and internal documentation and historical EVAs. Stakeholders within the EVA community, such as EVA flight controllers, support staff and instructors, were identified and a campaign of semi-structured interviews were conducted with these personnel at JSC during a 10-week period between May and August of 2014. The goal of the interviews was to gain an account of the activities and processes that occur during an EVA from the experts themselves. The semi-structured format relied on a preplanned set of questions to elicit interviewees' descriptions of working on EVA console, what sort of tasks they conduct, and who they communicated with during a mission. For those interviewees who had EVA flight controller certifications, interviews were audio recorded and later transcribed for qualitative data analysis. The remaining interviews were recorded via handwritten notes made by the interviewer.

\section{Apollo 16 EVA 4 Communication Analysis}

The second effort focused on describing a real-world EVA (Apollo 16 EVA 4) air-to-ground voice communication transcript. This EVA was conducted in a similar operational environment (i.e. to future possible asteroid redirect missions). A communication link analysis was performed to show the existence and frequency of communications between the primary operators within the domain [23]. The archived air-toground transcript of Apollo 16 EVA 4 was downloaded from the Apollo Lunar Surface Journal and analyzed [24]. The examined transcript, which includes pre and post EVA activities started at 212:44:37 ground elapsed time (GET) and ended at 228:03:00 GET (15.3 hours of audio).

Apollo 16 EVA 4's main objectives were to retrieve film cassettes from external storage compartments on the command module and conduct the Microbial Ecology Evaluation Device (MEED) experiment [25]. The EVA, from hatch open to hatch close, lasted 59.7 minutes and serves as the only deep space human EVA ever conducted that was not performed on the moon. The EVA operators within the transcript, described in Table II, consisted of the crewmembers and MCC CAPCOM. Ken Mattingly performed the EVA while John Young and Charlie Duke fulfilled the roles of IV. Henry Hartsfield filled the CAPCOM position until the completion of the EVA at which point Don Peterson took over the voice loop. 
Each instance of communication was examined using an adapted coding scheme previously used in Ref. [26], which examined communication patterns between members onboard a flight deck. Table II shows the coding structure delineated by operators, communication pathway, and communication content. Instances of communication loss and operator confusion were also coded. The destination of each communication instance by each operator was determined and classified into crewto-crew, crew-to-ground, and ground-to-crew pathways. The pathways were further examined for their content to reveal the demands and information needs of each operator. To assess the reliability of the coding, the transcript was coded from suit donning (216:44:41 GET) to equipment stowage (220:26:22 GET) by two judges. Percent agreement between the judges was $91 \%$. Discrepancies in codes were discussed between the judges until consensus was reached.

Table II. Apollo 16 EVA 4 Transcript Coding Scheme

\begin{tabular}{|c|c|c|}
\hline Type & Codes & Description \\
\hline \multirow{4}{*}{$\begin{array}{c}\text { EVA } \\
\text { Operators }\end{array}$} & MCC CAPCOM & Henry Hartsfield \& Don Peterson \\
\hline & Commander (IV) & John W. Young \\
\hline & $\begin{array}{l}\text { Command Module } \\
\text { Pilot (EV) }\end{array}$ & Thomas K. (Ken) Mattingly II \\
\hline & \begin{tabular}{|c|}
$\begin{array}{c}\text { Lunar Module Pilot } \\
\text { (IV) }\end{array}$ \\
\end{tabular} & Charles (Charlie) M. Duke, Jr. \\
\hline \multirow{3}{*}{$\begin{array}{l}\text { Comm. } \\
\text { Pathway }\end{array}$} & GtoC & $\begin{array}{l}\text { ground to crew communication } \\
\text { instance }\end{array}$ \\
\hline & $\mathrm{CtoC}$ & $\begin{array}{l}\text { crew to crew communication } \\
\text { instance }\end{array}$ \\
\hline & CtoG & $\begin{array}{l}\text { crew to ground communication } \\
\text { instance }\end{array}$ \\
\hline \multirow{8}{*}{$\begin{array}{l}\text { Comm. } \\
\text { Content }\end{array}$} & Query & \begin{tabular}{|l} 
questions asking 'What', 'When', \\
'Where' --e.g. "Do you know..."
\end{tabular} \\
\hline & Query Response & $\begin{array}{l}\text { response solely focused on the } \\
\text { question asked }\end{array}$ \\
\hline & Request & $\begin{array}{l}\text { request of an action or information } \\
\text { transfer }\end{array}$ \\
\hline & Request Response & $\begin{array}{l}\text { response to request of an action or } \\
\text { information transfer }\end{array}$ \\
\hline & Clarification & $\begin{array}{l}\text { additional information provided } \\
\text { beyond the initial query response }\end{array}$ \\
\hline & Reminder & $\begin{array}{l}\text { information provided (either } \\
\text { prompted or unprompted) }\end{array}$ \\
\hline & Update & $\begin{array}{l}\text { unprompted conveyance of } \\
\text { information }\end{array}$ \\
\hline & Acknowledge & $\begin{array}{l}\text { ensures information was received } \\
\text {-- e.g. "roger" or "okay" }\end{array}$ \\
\hline \multirow{4}{*}{$\begin{array}{l}\text { Comm. Issues } \\
\text { or Confusion }\end{array}$} & Comm. Loss & $\begin{array}{l}\begin{array}{l}\text { evidence of communication loss } \\
\text { (having to repeat statements) }\end{array} \\
\end{array}$ \\
\hline & Garble & incomprehensible phrase ('garble') \\
\hline & Crew Confusion & $\begin{array}{l}\text { evidence of crew confusion } \\
\text {-- e.g. "huh?.." }\end{array}$ \\
\hline & Ground Confusion & $\begin{array}{l}\text { evidence of ground confusion } \\
\text {-- e.g. "huh?.." }\end{array}$ \\
\hline
\end{tabular}

\section{Human EXtravehicular ACtivity}

The general purpose of EVA is to enhance the ability of the crewmembers to achieve mission success. As life support technology increased in reliability throughout the past 50 years, the confidence to pursue more complex EVA objectives also increased. EVA has become a workhorse for the NASA human space program in many duties because of astronauts' abilities to respond to unexpected failures and contingencies in real-time. Table III highlights some of the capabilities demonstrated by EVA to-date. The reader is encouraged to refer to Refs. [2], [3] for review of past EVA accomplishments and lessons learned. Much of the demonstrated capabilities of EVA will be needed to achieve mission success on future NASA missions.

In general, EVAs can be classified into three categories: scheduled, unscheduled and contingency [27]. The vast majority of EVAs performed to-date have been scheduled EVAs meaning the EVA was planned and practiced on the ground by all relevant personnel long before being performed in space. Scheduled EVAs have a dedicated planning period on the order of one year prior to astronaut egress, but can vary depending on EVA objectives. An unscheduled EVA is defined as an unplanned event that is considered essential to ensure mission success. While unplanned, an unscheduled EVA still receives a fair amount of timeline development and mission planning. The shortest duration planning period for an unscheduled EVA was 36 hours for EVA 21 which was recently performed on the ISS. Contingency EVA refers to an EVA that is safety critical to the crew. NASA currently has identified 12 main contingency EVAs which have procedures in place. To-date, none of those contingency EVAs have been performed during flight. It is also important to note that in addition to training for scheduled EVAs, crews also participate in training exercises to prepare for possible unscheduled and contingency EVA tasks.

Table III. EVA Purposes and Demonstration Flights [28]

\begin{tabular}{l|l|l}
\hline \multicolumn{1}{c}{ Purpose } & \multicolumn{1}{c}{ Reference Mission(s) } & \multicolumn{1}{c}{ Date (Yr) } \\
\hline \hline $\begin{array}{l}\text { Technology } \\
\text { Demonstration }\end{array}$ & Gemini 4, 10-12 & $1965 ; ' 66$ \\
\hline $\begin{array}{l}\text { Spacecraft and } \\
\text { Payload Inspection }\end{array}$ & $\begin{array}{l}\text { STS-37 (EVA 6); } \\
\text { STS-50 (EVA 6) }\end{array}$ & $1991 ; ' 92$ \\
\hline Spacecraft Servicing & STS-114 (EVA 3) & 2005 \\
\hline Payload Repair & STS-61 (EVA 23-27) & 1993 \\
\hline Payload Deployment & $\begin{array}{l}\text { STS-37 (EVA 14); } \\
\text { Apollo 16 (EVA 10) }\end{array}$ & $1991 ; ' 72$ \\
\hline $\begin{array}{l}\text { Scientific } \\
\text { Experimentation \& } \\
\text { Testing }\end{array}$ & $\begin{array}{l}\text { Apollo 16 (EVA 4); } \\
\text { Skylab (EVA 10) }\end{array}$ & $1972 ; ' 74$ \\
\hline $\begin{array}{l}\text { Device Installation } \\
\text { Structure } \\
\begin{array}{l}\text { Construction \& } \\
\text { Assembly }\end{array}\end{array}$ & $\begin{array}{l}\text { Skylab (EVA 4); } \\
\text { ISS (EVA 79) }\end{array}$ & $1973 ; ' 96$ \\
\hline
\end{tabular}

EVAs themselves can be decomposed into three primary phases: pre-EVA, EVA, and post-EVA. Pre-EVA tasks include all the preparatory work necessary to get both crew and systems ready for the EVA. The EVA phase consists of the execution of the EVA timeline while the airlock hatch is open. These activities include translating to the worksite, preparing the worksite for activity, performing the desired task(s), cleaning-up the worksite 
and translating back to the airlock for ingress. NASA defines an EVA as when the Extravehicular Mobility Unit (EMU) life support is separated from the spacecraft life support system. However, this study defines the hatch open and close actions to delineate the start and end of the EVA because this action is more readily identifiable within the available data sources (i.e. EVA transcripts, and video/audio files). Once back inside the spacecraft, the astronauts must doff the space suit, perform maintenance on the EMU and tools, and properly stow all equipment. Figure 1 below shows a representative EVA timeline breakdown by EVA phase and associated tasks. Figure 1 is meant to convey a notional nominal timeline that shows the various activities that are completed during an EVA. In order for these tasks to be accomplished, an entire support team works in tandem with the astronauts. These support personnel and the manner in which they provide support for the execution of these notional activities is the remaining topic of this section.

\begin{tabular}{|c|c|c|}
\hline EVA Phase & $\begin{array}{l}\text { Timeline } \\
\text { (Hr:Min) }\end{array}$ & Activity \\
\hline Pre-EVA & $-5: 00+$ & $\begin{array}{l}\text { - Crew rebreathe protocols } \\
\text { - Airlock preparations \& depress } \\
\text { - EMU check-out \& assembly } \\
\text { - Tool prep }\end{array}$ \\
\hline \multirow{8}{*}{ EVA } & $0: 00$ & Crew Egress \\
\hline & $1: 00$ & Translation to worksite \\
\hline & $2: 00$ & Worksite setup \\
\hline & $3: 00$ & \multirow{2}{*}{ Perform worksite task(s) } \\
\hline & $4: 00$ & \\
\hline & $5: 00$ & Worksite cleanup \\
\hline & \multirow[t]{2}{*}{$6: 00$} & Translation to airlock \\
\hline & & Crew Ingress \\
\hline Post EVA & $7: 00+$ & $\begin{array}{l}\text { - Airlock repress \& cleanup } \\
\text { - Tool evaluation \& breakdown } \\
\text { - EMU doffing \& maintenance } \\
\text { - Equipment stowage } \\
\text { - Crew Debriefs }\end{array}$ \\
\hline
\end{tabular}

\section{Figure 1. Notional EVA timeline with representative tasks.}

During real-time operations, an EVA can be described as operating within two modes: nominal or off-nominal. Nominal indicates that all tasks are proceeding without any issues and that the procedures and systems are adhering to the planned timeline. Off-nominal situations represent any instances that deviate from the nominal timeline. Figure 2 shows a comparison between nominal and off-nominal timeline margin as a function of location within a representative EVA timeline. To assist the EVA operator in both modes of operation, a document known as a crib sheet is produced. This document provides task instructions and suggestions for nominal operations and also includes information for contingencies that may arise during the EVA. EVA operators develop a crib sheet that addresses as many situations as possible that could arise during the EVA, e.g. equipment failure, unexpected worksite configuration, etc. The crib sheet document contains vetted task procedures to ameliorate off-nominal situations, which could possibly impact the timeline positively or negatively.

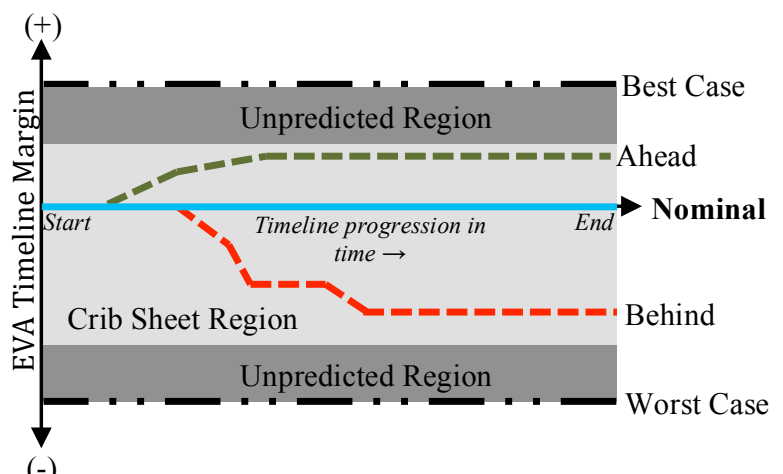

Figure 2. EVA Modes of Operation

Timeline margin, as shown in Figure 2, refers to the capacity for the EVA to complete a predefined set of tasks within an allocated amount of time. The crib sheet region represents the limitations imposed on the EVA due to finite training preparation and EVA resources. The crew can only train for a finite set of possible tasks and the EVA resources, such as the crib sheet, can only account for a limited set of possible scenarios. Outside this region exists the unpredicted region, where situations are unfamiliar and potentially life threatening.

Positive timeline margin indicates more tasks can be completed than planned, thus the timeline can be ahead of schedule. These tasks are usually called "get ahead" tasks and are planned, just in case positive margin in the timeline arises. EVA timelines are constructed today with an a priori knowledge that on orbit task performance is usually more efficient than on ground training performance, due to the absence of drag forces present in simulation environments such as the Neutral Buoyance Lab (NBL), which results in positive timeline margin [29]. Negative timeline margin means less tasks can be completed than originally planned, thus the timeline can fall behind schedule. This situation can arise for a variety of reasons including but not limited to hardware malfunctions and $\mathrm{EV}$ crew translation difficulties.

The best and worst case modes of operation represent idealized limits as to how much ahead and how far behind the EVA timeline progression can become. For instance, the worst-case timeline would result in no planned tasks being accomplished. The best-case timeline would mean that more tasks than even the preplanned "get ahead" tasks were accomplished.

\section{Nominal Operations}

During the nominal mode of operation, the communication chatter on the air-to-ground link is kept at a minimum. The nominal mode during EVA is analogous to the "Quiet or Dark Cockpit" nominal operations mode of Boeing aircraft $\{$ Stoll $\}$. Timeline procedures are relayed via the IV crewmember and status updates and 
confirmations are sent by the EVA crewmembers as needed. There are periodic status updates sent between the EVA MCC operators. The crib sheet, utilized in the nominal mode of operation, serves as a quick reference for helpful hints and instructions to keep deviations from the nominal timeline at a minimum.

\section{Off-Nominal Operations}

The nominal timeline includes the "must-have" tasks. To help ensure these tasks are accomplished, the crib sheet is usually weighted to account for more negative offnominal situations. The amount of communication between EVA operators usually increases with the number of the off-nominal events. Also, the more life threatening the situation, the more people become involved. In extreme cases additional personnel known as Team 4 are called in to troubleshoot with MCC personnel. Their involvement is beyond the scope of this study.

A great deal of time and effort is devoted to crib sheet development. But even with years of experience and planning there is always the element of unknown when operating an EVA. As a testament to the members of the EVA community, no loss of life situations have occurred during EVA, to-date. However, $36 \%$ of all EVAs performed until July 2011 have experienced a significant incident of some kind (e.g. systems issues, operational failures, etc.) as defined by the NASA Flight Safety Office [1].

\section{EVA INFORMATION FLOW MODEL}

The results presented in this section are a synthesis of information from the various data sources described in Section 2. First, primary and secondary operators' roles and responsibilities are discussed. Then, an information flow model of the EVA domain is presented highlighting the communication pathways between EVA operators as shown in Figure 3.

\section{EVA Operators}

This study classifies EVA operators into two groups: primary operators are those personnel who are directly involved with the real-time EVA timeline execution and crew safety, and secondary operators are those personnel that provide support to the primary operators. All personnel are tasked with the responsibility of maintaining crew safety. The distinction made here between the operators is to help breakdown the work domain for discussion purposes.

Primary operators consist of the crewmembers (Extravehicular (EV), and intravehicular (IV)), and MCC personnel (the Flight Director, the Capsule Communicator (CAPCOM), the EVA Flight Control Room (FCR) personnel, and the EVA Multi-Purpose Support Room (MPSR) personnel).
Astronauts fulfill the role of the EVA crewmembers and typically serve as the IV crewmember and/or CAPCOM. Current day operations of EVA invoke a buddy system where the lead EVA crewmember (EV1) and his/her partner (EV2) work collaboratively to achieve the EVA objectives. The EVA crewmembers are the actuators within the EVA domain, physically manipulating the external environment around the spacecraft. They are tasked with properly executing the EVA timeline in an efficient and safe manner. Their work environment is constrained by their EMU, their worksite and their physical and mental capabilities (see Refs [30], [31] for detailed descriptions of EVA work environment).

At the top of the MCC hierarchy is the Flight Director whose ultimate role is to act as the governing authority to maintain crew safety and ensure overall mission success. The Flight Director has final authority over all decisions that are made during the entire mission, not just during the EVA. This operator must manage the decisions governing the entire human/spacecraft system.

CAPCOM is the only person, along with the IV, in the MCC allowed to verbally communicate directly with the crew. They serve as the focal point of the information generated within MCC and the information coming from the crew.

The IV crewmember is the EVA field marshal, dictating the pace and productivity of the EVA by verbal communication with the EV crew and MCC. ISS operations incorporate a ground IV whereas past programs such as the shuttle program placed the IV crewmember onboard the spacecraft. In either case, they closely monitor EVA progress with the intent of minimizing error in task performance. They control the EVA checklists and procedures and manage the integration of all communication flow between the EVA crewmembers and MCC personnel. They are also heavily involved in the pre-EVA procedures as well as the postEVA tasks, ensuring all procedures and checklists are properly completed.

The EVA FCR is the lead EVA team member in MCC who is responsible for coordinating all EVA activity in the MCC, which includes maintaining accurate console logs, tracking the positive/negative timeline margin based on the planned timeline, reporting anomalies, assessing the impact of those anomalies on EVA operations, and recommending appropriate action to the Flight Director. This operator leads the EVA team on all aspects of the EVA from pre to post EVA tasks and interfaces with pertinent MCC FCR personnel as needed. They are also responsible for the development of the EVA checklists and procedures.

To support the tasks and responsibilities of the EVA FCR, there exist three positions within the MPSR known as EVA Task, EMU Systems, and Airlock Systems. These operators are the handlers of the raw data sent from the 
crew and spacecraft to MCC. It is common to have one or more support personnel such as those doing on the job training sit along these MPSR operators to assist them in their duties.

The EVA Task primary role is to monitor and manage the progression of the EVA tasks within the timeline. This MCC position is the EVA expert for all task procedures and responds to any task anomalies or problems that may arise during the EVA. EVA Task handles the execution of task workarounds and coordinates procedural updates with the rest of the EVA support team. EVA Task is also tasked with the responsibility of tracking tool usage and stowage. Their primary data sources are audio and video downlink to track EVA progression.

The responsibility of the EMU system rests with the EMU Systems operator, who handles all system monitoring, configuring, and troubleshooting that may arise during the EVA. EMU Systems also provides EMU system updates such as consumable status to the rest EVA support team, and assesses the impact of the EMU on the EVA timeline and assists in monitoring crew health. EMU Systems is the primary tracker of the crew's limited consumables (i.e. $\mathrm{O}_{2}, \mathrm{CO}_{2}$, power, etc.) and reporter of crew status to the rest of the EVA Operators. Their main data sources in addition to the audio and video downlink is the EMU suit telemetry.

During the pre-EVA and post-EVA, an Airlock Systems operator manages tasks related to airlock operations. Responsibilities include aiding in some EMU system monitoring alongside the EMU Systems operator, but mainly coordinating EVA tasks that interface with airlock systems. Also, the Airlock Systems operator assesses timeline alterations with airlock considerations and provides recommendations and workarounds to the rest of the EVA support team. Airlock Systems leverages the telemetry data as well as the audio and video data to monitor and maintain understanding of the vehicle systems as it pertains to EVA interfaces.

The remainders of the EVA support staff are classified as secondary operators, which consist of a multitude of personnel, more than there is room for in this one study to discuss in detail. In summary, secondary operators provide supplementary information and support to the primary operators pertaining specifically to EVA. These operators include, but are not limited to, flight controller consoles such as the Flight Surgeon, the Environment Control and Life Support Systems (ECLSS), Operations Support Officer (OSO), Robotics Operations Systems Officer (ROBO) and Communications and Tracking Officer (CATO) in MCC FCR. The examination of all FCR console positions is outside the scope of this study but the reader is encouraged to consult Ref. [32] for further detail of MCC operations. Each MCC FCR operator has MPSR consoles that provide additional support and analysis capability. In addition to these personnel, there exists another layer of support that includes Mission Evaluation Room (MER) operators and SAFETY. These positions provide the "nuts and bolts" systems knowledge to the rest of the support team. Additional operators also include all the support facilities staff who were involved with the EVA tool development, testing, and training of the EVA crew. Examples of such facilities include the Neutral Buoyancy Lab (NBL) and Virtual Reality Lab. An overview of these facilities and more can be found in Ref. [33].

\section{EVA Information Flow Model}

With the primary and secondary operators in mind, the communication pathways between each can be examined, and summarized in an information flow model in Figure 3. The information flow model provides a framework to describe the information transfer during EVA support and identifies areas of potential disturbances in communication transfer.

Each of the primary operators within MCC are represented by ovals and the secondary operators are grouped together within relevant support groups. MCC artifacts, which are uniform throughout all the console positions are also provided. Arrows are used to display the primary linkages and modes of communication between each console position during a nominal EVA operations. Each shaded region displays the relative proximity between each operator. For example, the MCC FCR operators are all co-located in the same room which allows for verbal and nonverbal communication in addition to the voice loops and console systems. Disturbances in communication are indicated by lightening bolts.

The highest priority communication pathway is the air-toground transmissions, which all operators listen to at all times. But only a select few operators (the crew members, ground IV and CAPCOM) can speak on this voice loop. The information flow exhibits a top down hierarchy with information flowing down from the in-space crew to the various support teams. Each operator utilizes a multitude of data sources, but specifically uses electronic flight notes (EFNs), mission action requests (CHITs), JEDI messages, the Anomaly database, electronic crew timeline (OSTPV), and change requests (CR) data entry systems for real-time data processing and transfer. Each position is also responsible for accurately logging their activities within their electronic console logs. In addition to their electronic resources, each console position has copies of the MCC flight rules and console specific handbooks. Both these documents are an assimilation of best practices and guidance expected to be implemented during support operations. 


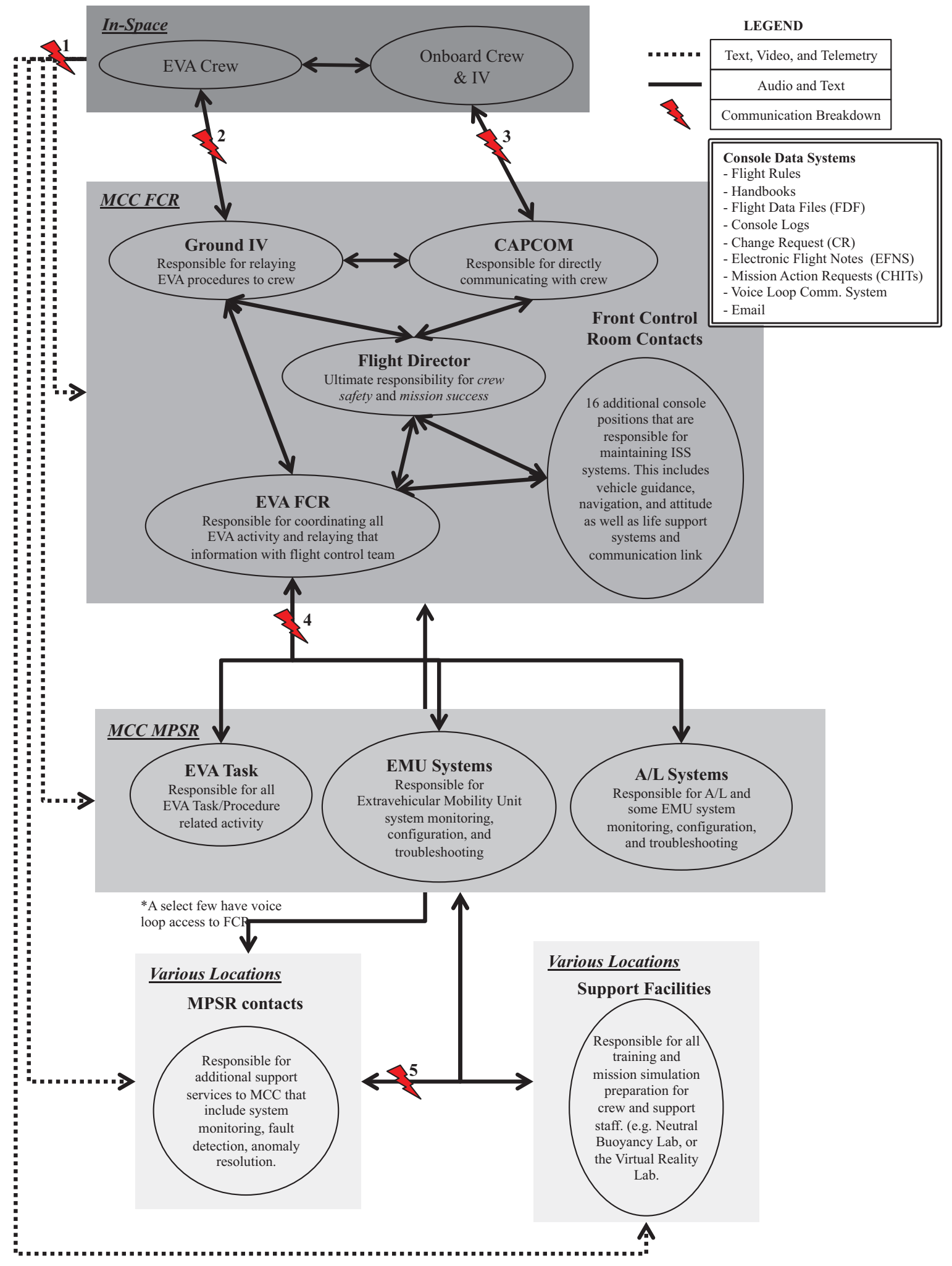

Figure 3. EVA Information Flow Model 
The MPSR operators handle and analyze the raw data which consists of audio, video, text and telemetry. They then pass along their interpretations and recommendations to the MCC FCR personnel. Within the MCC FCR, the information then flows through the Flight Director. The Flight Director interacts directly with the EVA FCR for EVA related activity, and also maintains contact across all the other FCR consoles to maintain system wide understanding. The information from EVA FCR is passed to the ground IV and/or CAPCOM depending on the relevancy of the information. Non-EVA related systems knowledge is primarily channeled via the CAPCOM and EVA relevant information is transmitted via the ground IV. Personnel preference dictates whether the information is verbally re-communicated by the Flight Director to CAPCOM or ground IV, or rather simply agreed upon by verbal or nonverbal communication. There also exists a communication channel between the Flight Director, Ground IV, and EVA FCR that occurs face to face and is not over the voice loops.

Another area of important communication traffic is between the EVA FCR and the EVA MPSR, who are located in separate control rooms (same building). They rely on the voice loops and console data entry systems as a means to transmit their knowledge of the EVA systems and timeline progress. The EVA FCR is concerned with integrating the various aspects of the EVA such as timeline and EMU consumables, and relies on EVA Task and EVA Systems to provide that material, respectively.

To aid in their monitoring and anomaly resolution capabilities, the EVA MPSRs rely on input from the various MPSR support operators. The Mission Evaluation Room (MER) is an important source of data for the EVA MPSR operators. The EVA MER operators in particular convey the necessary technical details of the tools and equipment needed by the MPSR and FCR personnel and provide an additional level of system monitoring, fault detection, and anomaly resolution.

Disturbances in communication among the EVA operators can occur, even in the most ideal nominal realtime situations. The air-to-ground transmission can experience loss of signal events, indicated by lightning bolts 1,2 , and 3 , which prevent communication and data transfer. Video data is lost more frequently than audio data, which impairs MCC situation awareness. These events typically have a duration on the order of a few seconds to tens of minutes. During this time, the crewmembers and MCC are forced to work in an isolated fashion relying on the EVA timeline, checklist, and personal experience until communication can be reestablished. In addition to loss of signal disturbances, EVA crewmembers have suffered from periods of tunnel vision which impairs their ability to maintain their spatial and mental awareness which is compensated by close monitoring by MCC. Finally, communication between the all operators is complicated by the desire not to interrupt each other. There is a lot of information that must be channeled between the operators in a succinct and efficient manner as possible.

Two other disturbances exist which are identified by lightning bolt 2 and 3 . They include EVA timeline alterations and spacecraft updates. EVA replanning requires the ground IV to adequately relay that information to the crewmember for implementation. Poor communication, and lack of specific knowledge can lead to improper task execution. From a spacecraft perspective, CAPCOM must perform similar duties in ensuring the spacecraft systems are updated to the necessary configurations to aid in EVA execution (i.e. ensure the electrical system is turned off and on when a module is replaced by a crewmember). Common practice in performing real-time EVA modifications is to send a preliminary outline of the changes to the crewmembers, to let the give feedback. However, if changes are made during the EVA phase, replanning instructions are primarily restricted to audio communication with limited time for discussion of the changes due to time constraints.

Communication disturbances are also present between the MCC operators as highlighted in lightning bolts 4 and 5 . The EVA FCR is concerned with "big picture" items such as overall timeline execution and EVA integration with other spacecraft subsystems where as the MPSR operators are concerned with the minute by minute details. In particular, the MPSR operators are constantly monitoring real-time flight data and comparing that information with their own expected values (trend monitoring). Data trends either follow what they expect or they deviate; but in either case, MPSR operators must inform the EVA FCR of their status. The threat of information overload and of inadequate knowledge transfer between these operators are ever present. As indicated by lightening bolt 5 , there also exists the threat of over reliance on the MPSR support teams such as MER by the MPSR and MCC. This additional layer of EVA support also introduces additional opportunities for poor communication and inadequate coordination.

Additional considerations exists that are not limited strictly to the EVA support operators. The MCC has a structured authorization process, where the Flight Director has final authority on transmissions sent to the crewmembers. Even already preapproved EVA procedures, such as those on the EVA crib sheet, must pass through the proper channel for authorization in realtime. Additionally, there are many voice loops running concurrently that must be synthesized by many operators. The risks of task saturation and information overload were repeatedly mentioned during the interviews as commonplace among most operators during real-time operations. 


\section{Apollo 16 EVA 4 Communication ANALYSIS}

The results presented in this section are an analysis of an actual EVA voice transcript. Future EVAs, which take place beyond LEO, present a unique operational challenge and is the motivation for this work. To that end, a communication analysis was conducted of the only nonterrestrial "deep space" EVA to be conducted by NASA, Apollo 16 EVA 4 that is indicative of a nominal EVA. This work highlights the communication pathways between EVA operators and the content of those communication instances.

First, the communication pathways are described, and then the content results are presented. The crewmembers generated 75 percent of all instances of communication and the MCC supplied the remaining 25 percent. Figure 4 shows the volume of communication transfer for crew to crew and crew to ground pathways for each crewmember.

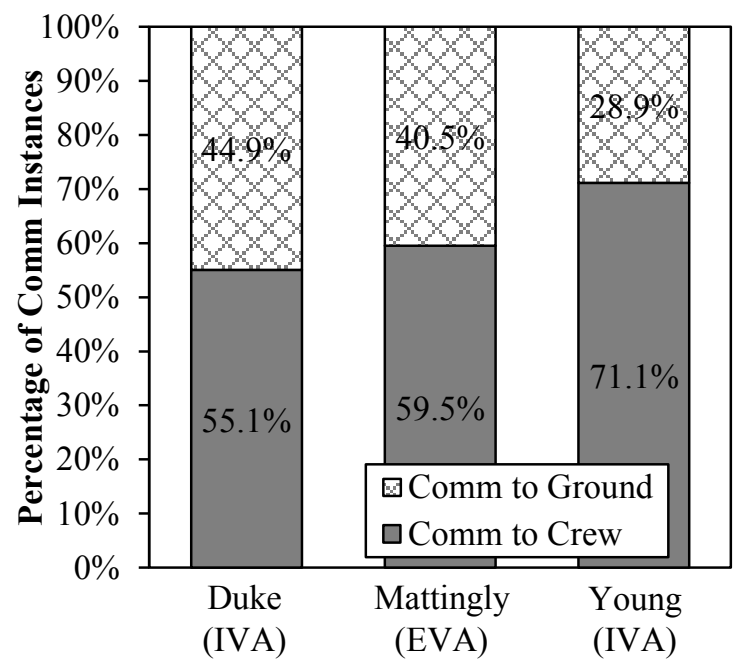

Figure 4. Total onboard crew communication between other crewmembers and ground crew.

Duke and Young provided Intravehicular Activity support while Mattingly conducted the EVA. Young's IV support was involved specifically in meeting Mattingly's needs whereas Duke focused his work more on the vehicle systems. Duke and Mattingly spent approximately 55 to 60 percent of their time conversing with the onboard crew, whereas Young spent $71 \%$ of his communication with the onboard crew. As for CAPCOM, Figure 5 shows their communication instances were clustered towards the pre and post EVA phases. CAPCOM utilized only $7 \%$ of their total communication instances during the EVA.

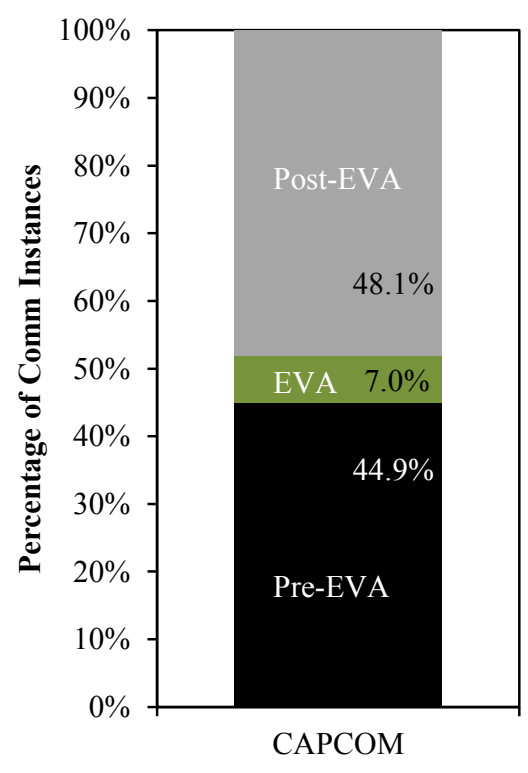

Figure 5. Ground crew communication sent to onboard crew during all phases of EVA.

The communication pathways were then divided among the three separate EVA phases for each of the onboard crewmembers. Figure 6 show the percentage breakdowns for the pre-EVA, EVA, and post-EVA phases, respectively. The pre-EVA phase exhibited $50 \%-60 \%$ crew-to-crew communication. These conversations pertained primarily to vehicle configuration topics and timeline status updates. Throughout the transcript there were periods where voice communication was used to realign MCC and crewmembers as to their progression within the timeline. Paper checklists and procedures were leveraged for almost all activities. When the timeline entered the EVA phase, communication patterns shifted to crew-to-crew instances. Mattingly utilized voice communication as a means to continually update the team on his progress and status. Several instances of him thinking aloud were displayed.

Note that even though the communication was predominately crew-to-crew communication, the ground was a passive listener in all communication instances, participating in the conversation during periods of high importance such as the MEED experiment. Once the EVA was completed, the majority of the conversations once again shifted, except crew-to-ground communication became the dominant pathway. This trend can be attributed mostly to the debriefing and vehicle configuration conversations that occurred post EVA. 


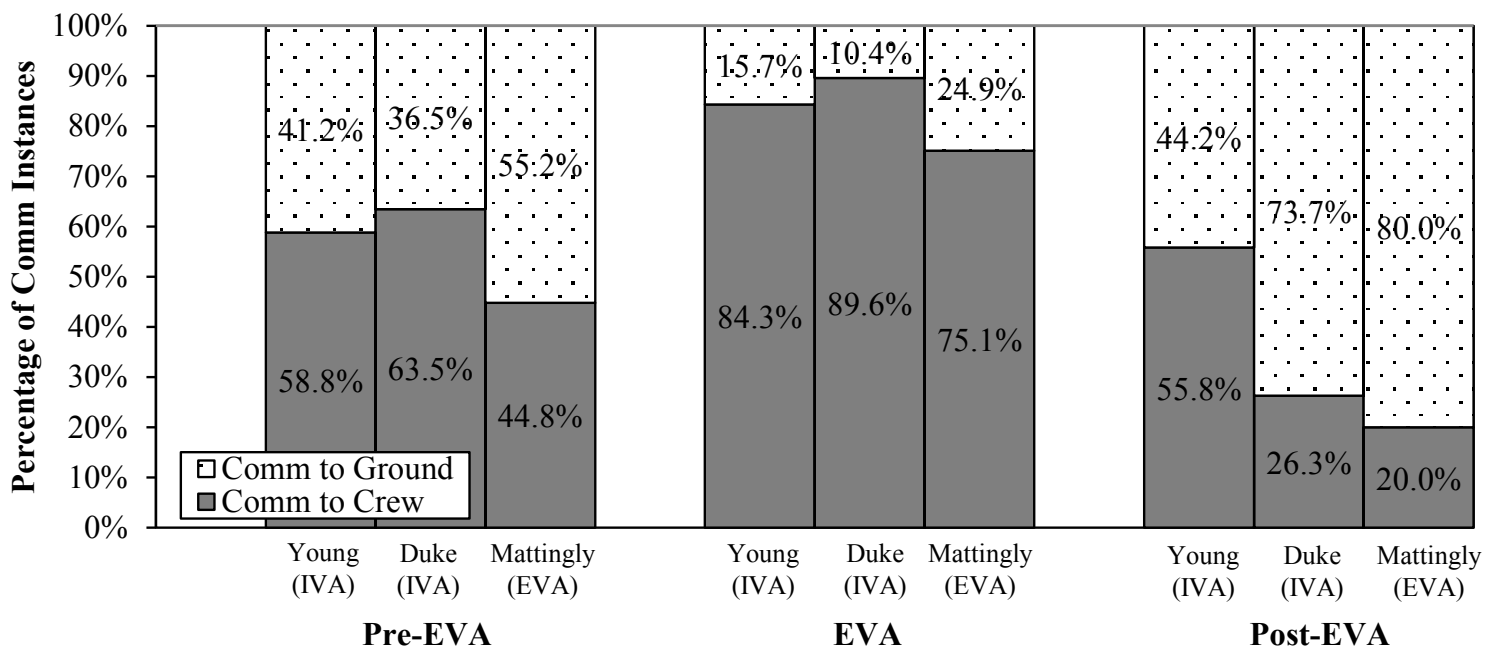

Figure 6. Onboard crew communication between other crewmembers and ground crew during Pre-EVA, EVA, and Post-EVA activities.

As previously shown in Figure 6, the dominant communication pathway varies depending on the various stage of the EVA timeline. This trend is also reflected in Table IV, which shows the communication instance frequencies within each EVA phase. Crew/Ground pathways maintain a steady rate of approximately one instance per minute, peaking at about three instances per minute during the EVA, whereas the crew/crew interaction increases tenfold during the EVA phase. This can be primarily attributed to the increased rate of status updates made by the EV crewmember as he conducted his activities outside the spacecraft.

Table IV. Communication instance frequencies (instance/min).

\begin{tabular}{|c|c|c|c|}
\hline & Pre-EVA & EVA & Post-EVA \\
\hline Crew/Cre & 0.68 & 11.38 & 0.26 \\
\hline Crew/Ground & 1.3 & 3.53 & 1.03 \\
\hline Total Comm. & 1.99 & 14.92 & 1.29 \\
\hline
\end{tabular}

Figure 7 shows a more detailed time-elapsed evolution of the communication instances among the operators. Crew/crew communication instances are shown alongside crew/ground instances with major EVA timeline milestones such as suit donning and hatch opening and closing. The shaded region that includes suit donning to the start of equipment stowage identifies the region where the communication content analysis was applied, as described in Table II.An almost constant rate of communication is shown in between the two CAPCOM personnel even during regions of increased crew/crew communication. As expected, the EV crewmember displayed the greatest number of communication instances. Areas of increased communication occurred during major events in the EVA timeline such as suit donning, cabin depress, and hatch operations. MCC maintained close communication pathways with each of the major timeline events. One area that displays a sharp increase in communication rates is during the MEED experiment, which required a precise timing of sample exposure. IV communication patterns also provide some insight into the delineation of their IV responsibilities. Young displayed a communication pattern that more closely mirrors Mattingly indicating that his role was geared towards immediate EVA support. Young verbally conducted the pre-EVA checklist and ensured the suits were donned appropriately. Duke maintained a more indirect support role during the EVA by maintaining onboard systems and interacting with MCC predominately during post-EVA. 

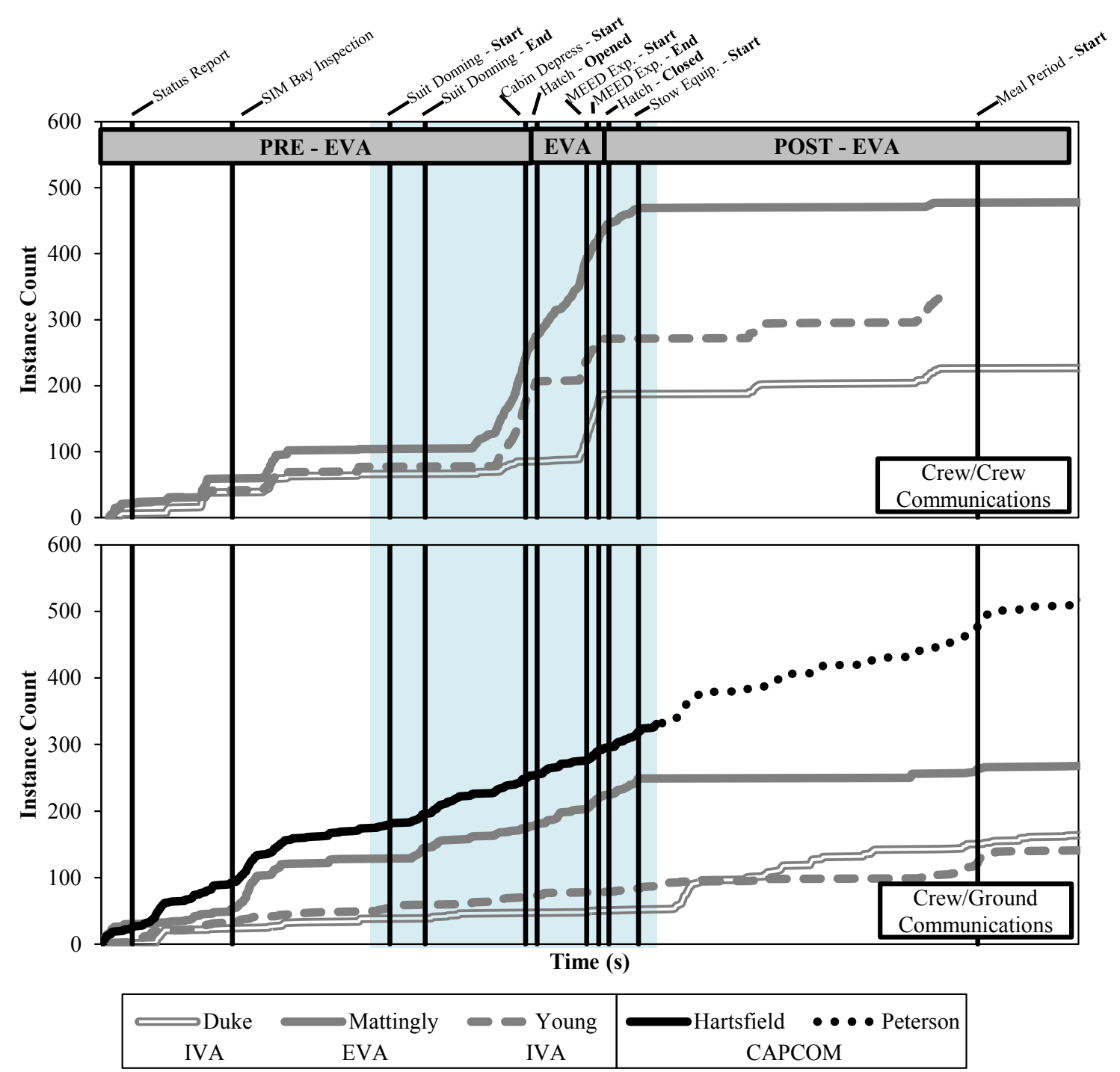

Figure 7. EVA operators' communication instances as a function of time.

The shaded region of was examined in more detail for the content of the communication instances. The content breakdown for each operator is shown in Figure 8. Note that the individual percentages of each operator when summed together do not total $100 \%$ because for many of the instances, multiple codes were applicable. For example, during Mattingly's inspection of hardware during EVA he said to MCC:

\section{(219:06:17 GET) "Okay, anything else on the aft end? I don't see any blistering of paint or anything. It's all clean in the aft shell."}

The first portion of Mattingly's instance indicated an acknowledgement to CAPCOM's pervious communication instance as well as a query. He then provides additional clarification to supplement his query. Many of the overlapping codes $(10<$ instances $<20)$ occurred in pairs such as Query/Request Response, Query/Clarification, Query/Update, Query Response/Clarification,
Update/Clarification, and Request/Update. The Acknowledge code was almost universally paired with another code, particularly with Query and Request (over 60 occurrences).

Each operator displayed a consistent pattern in acknowledging communication transmissions. This is likely attributed to standard etiquette present in military radio speech. CAPCOM in particular made sure to acknowledge proper transmission and understanding from the crew. CAPCOM also spent $26 \%$ of their communication instances responding to questions the crewmembers asked. A subtle yet important role CAPCOM played was with regards to providing reminders for the crewmembers. On multiple occasions, the crew utilized CAPCOM as an external timer and procedure reminder. The crewmembers off-loaded memory related information to CAPCOM, which was then returned at the desired time in the timeline. An example of this is shown below where Young requested MCC to remind 
the crew to close a valve when a particular pressure value was reached.

\section{(218:38:41 GET) "Okay. Houston, can you give us a call at $3.25 ? ”$ \\ (218:38:45 GET) " "Will do."}

Out of the crewmembers, Duke spent more time responding to questions and requests. Young spent a large portion of his communication instances making requests and asking questions. Young's communication content aligns with his role as the primary IV support to Mattingly, especially in the pre-EVA and EVA phases. Mattingly spent much of his time updating the rest of the operators of his precise location within the EVA timeline as well as asking questions. He provided details such as particular details in handling of the equipment and current equipment configurations to ensure proper EVA execution.

\begin{tabular}{|ll|}
\hline Query & $\square$ Query Response \\
⿴囗Request & $\square$ Request Response \\
⿴囗十arification & $\square$ Reminder \\
囷 Update & $\square$ Acknowledge \\
\hline
\end{tabular}

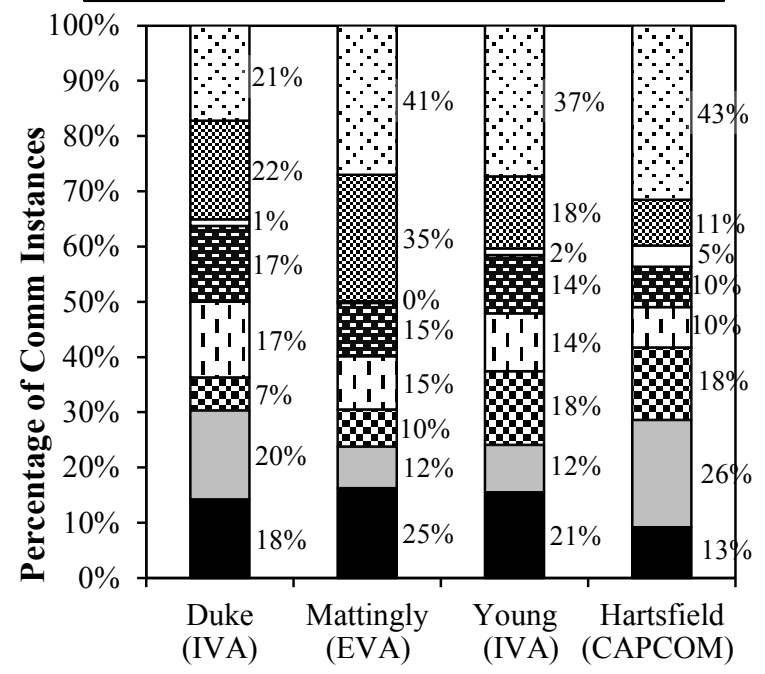

Figure 8. EVA operators' communication content breakdown

\section{DisCuSSION}

Present-day EVA support structure is arranged to meet the needs of ISS operations. As highlighted in the information flow, the ground IV is located in MCC instead of on station. Two primary reasons exist for this configuration, the first being that there are typically only three American astronauts onboard the ISS at one time. Two of these people are dedicated to conducting the EVA and the third person is usually dedicated to operating the ISS robotic arm to support the EVA (e.g. relocate cargo and equipment), leaving no one available to perform IV tasks onboard. The second reason is that the EVAs being conducted are typically not recently rehearsed before performing due to the long duration spaceflight times (upwards of 6 months). Any changes made to the EVA timeline are better understood by a ground IV who participated in the development of those changes. They can then translate those changes to the onboard crew. This work flow leads to a high level of adaptability for current ISS EVAs. The crew train for their planned EVAs but if timelines change, at least one of the immediate crewmembers (the ground IV) is well acquainted with the changes. This configuration is in contrast to the shuttle missions where EVA efficiency was more important than adaptability since the shuttle missions had a limited mission duration typically less than 14 days. Every minute mattered which meant that an onboard crew member or two was dedicated to ensuring the IV roles and responsibilities were met. The Shuttle approach to EVAs, however, required an incredible amount of preplanning and the time between training and actually performing the EVA was kept to a minimum.

In the context of future deep space, time-delayed communication missions with length mission durations, it is likely that the reemergence of dedicated onboard IV crewmembers will occur, similar to the two-IV configuration seen in Apollo 16 EVA 4. In fact, the design of Orion will not be that dissimilar from the Apollo capsule. Just like the crew in Apollo 16 EVA 4, all crew members will have to don their spacesuits and depress the cabin for EVA capability. However, the element of adaptability will also be present given the lengthy mission timelines. Ensuring both adaptability as well as efficiency in the presence of timedelay will stress the current EVA support structure. Results from analog missions have shown that multiple IV onboard crewmembers help alleviate this stress [34], however, the specific reasons for this trend remains largely unanswered.

The information flow model shows that EVA support is a complex work domain. While the astronauts assume the greatest personal risk in conducting the spacewalk, it is up to the rest of the team to minimize that risk by ensuring that the EVA crewmembers' environment, systems, and tools are operational and safe. The vast amount of domain knowledge that exists within MCC is unlikely to be transferred completely onboard in the near future via automated systems due to technological limitations. Future missions will still require significant human support input into the EVA work domain, and the role of advanced technology in this timedelayed environment is yet to be determined. Transferring at least some aspects of MCC real-time support capabilities onboard could alleviate some of the time-delay communication challenges between crew and ground. The proper function allocation between $\mathrm{MCC}$ and onboard automated systems for EVA support is another open ended topic. Crew training and planning will also likely play a key role in alleviating some of the time delay challenges.

It is important to consider all aspects of an EVA, including pre and post EVA activities. As seen in the Apollo EVA, the dialog between crew and ground is elevated during pre and post EVA activities. Even during the EVA, where ground communication frequencies were found to be 3 instances per minute, time-delay of even tens of seconds will have an immediate impact. To-date, analog studies such as the RATS 
and NEEMO missions have had some success at demonstrating nominal EVA operations by incorporating the time-delay into the EVA planning. However, the NASA AMO study, has demonstrated the coordination capability between crew and ground can break down in the presence of time-delay under current operating practices, even with rudimentary mitigation tools. The majority of communication instances of between crew and ground operators in the case study pertained to queries, requests and their associated responses which indicates the inherent reliance each EVA operators has on one another. Finding alternative methods, possibility via technological means, to answering these queries and requests will prove useful in operating in time-delay.

\section{Limitations of study}

The applicability of the findings in this study require some discussion. The information flow model was constructed via a limited set of meetings and interviews with EVA domain experts with varying degrees of experience. The limited number of EVAs conducted per year prevented an actual observation of an EVA during the course of this study which limited the resolution of the details within the flow model.

As for the communication analysis of the Apollo 16 EVA 4, the technologies utlized during this EVA are out of date compared to present day standards but it does provide some insight as to how a crew can execute an EVA with limited ground dialog. The EVA itself was fairly simple in complexity and the duration was a fraction of the EVA durations conducted today. The purpose of the EVA was to execute a science objective, which is a likely objective in future EVA missions.

\section{Conclusions ANd Future Work}

This work sought to explore the EVA domain, given the lack of formal explanations in the literature. Contextual inquiry was leveraged, specifically an information flow model was constructed, to explain the key operators and their respective roles. This model identifies the complex communication pathways that exist to provide real-time support to EVA crewmembers and disturbances to those communication pathways. The EVA domain was shown to be a dynamic environment in which there exists much interaction within MCC to support the EVA crewmembers. MCC provides vital contributions to the execution of the EVA such as consumable tracking, and anomaly resolution.

A communication analysis of an historical flight transcript was also conducted to provide further context of the EVA domain, as it pertains to operations beyond LEO. The communication pathways were quantified and a content analysis was performed to gain a understanding of the operator needs and demands. Some key results of this work is that a majority of communication instances are devoted to asking and responding to questions and requests. MCC performs a wide array of roles ranging from answering questions to acting as a reminder to requesting tasks to be completed. Future work should attempt to leverage not only
Apollo EVAs but also Shuttle and ISS flight data to gain additional insight into EVA operations.

Extending the current EVA support configuration to future time-delayed missions raises areas of future research. There is a need to better understand the nominal and off-nominal modes of operation in time-delay scenarios from a MCC perspective. Also, future EVAs will likely have additional EVA operators such as scientists involved in EVA exploration which is different from current day operations. How will the vast knowledge that exists with MCC be appropriately conveyed to EVA crew when needed? This question emphasizes the need for further research into current day operations for insight into future operations. Appropriate function allocation of MCC capabilities split between human and automated systems is an immediate area of potential research. The EVA domain is ripe with potential as an area of research for future decision support system technology to alleviate the time-delay impacts on EVA operations.

\section{ACKNOWLEDGEMENTS}

This research was sponsored by the NASA Space Technology Research Fellowship - Grant \# NNX13AL32H. The authors would like to thank all those from the NASA community who participated in meetings and interviews as well as the anonymous reviewers for their guidance in the revisions of this manuscript.

\section{REFERENCES}

[1] D. Pate, "Significant Incidents and Close Calls in Human Spaceflight: EVA Operations," S\&MA Flight Safety Office, JS 2011 010, Aug. 2011. R. C. Wilde, J. W. McBarron II, S. A. Manatt, H. J. McMann, and R. K. Fullerton, "One hundred US EVAs: A perspective on spacewalks," Acta Astronautica, vol. 51, no. 1, pp. 579-590, Jul. 2002.

[3] I. I. McBarron and W. James, "Past, present, and future: The US EVA Program," Acta Astronautica, vol. 32, no. 1, pp. 5-14, 1994.

[4] B. G. Drake, Ed., "Human Exploration of Mars Design Reference Architecture 5.0," NASA Headquarters, NASA/SP-2009-566, Jul. 2009.

[5] P. Lopez, M. Mcdonald, J. Caram, H. Hinkel, J. Bowie, P. A. Abell, B. G. Drake, R. M. Martinez, P. W. Chodas, K. Hack, and D. D. Mazanek, "Extensibility of Human Asteroid Mission to Mars and Other Destinations," presented at the 13th International Conference on Space Operations 2014, Pasadena, CA, 2014.

[6] D. Zimmerman, S. Wagner, and B. Wie, "The First Human Asteroid Mission: Target Selection and Conceptual Mission Design," presented at the AIAA/AAS Astrodynamics Specialist Conference, Toronto, Canada, 2010.

[7] P. W. Felker, "Using Optimization to Improve NASA Extravehicular Activity Planning," Masters Thesis - Naval Postgraduate School, 2012. 
[8] J. J. Marquez, "Human-Automation Collaboration: Decision Support for Lunar and Planetary

Exploration," PhD Thesis - MIT, 2007.

[9] J. R. Norcross, K. G. Clowers, T. Clark, L. Harvill, R. M. Morency, L. C. Stroud, L. DeSantis, J. R. Vos, and M. L. Gernhardt, "Metabolic Costs and Biomechanics of Level Ambulation in a Planetary Suit," NASA, NASA/TP-2010-216115, Feb. 2010.

[10] E. S. Patterson, D. D. Woods, and J. Watts-Perotti, "Voice Loops as Coordination Aids in Space Shuttle Mission Control," Computer Supported Cooperative Work, vol. 8, no. 4, Oct. 1999.

[11] J. Watts-Perotti and D. D. Woods, "How anomaly response is distributed across functionally distinct teams in space shuttle mission control," Journal of Cognitive Engineering and Decision Making, vol. 1, no. 4, pp. 405-433, 2007.

[12] J. F. Kubis, J. T. Elrod, R. Rusnak, and J. E. Barnes, "Apollo 15 Time and Motion Study," NASA, CR-128695, Jan. 1972.

[13] J. F. Kubis, J. T. Elrod, R. Rusnak, J. E. Barnes, and S. C. Saxon, "Apollo 16 Time and Motion Study,” NASA, CR 128696, Jul. 1972.

[14] C. A. Looper and Z. A. Ney, "Extravehicular activity task work efficiency," presented at the 35th International Conference on Environmental Systems (ICES), Rome, Italy, 2005.

[15] C. Looper and Z. Ney, "Quantifying EVA Task Efficiency," presented at the SpaceOps 2006 Conference, 2006.

[16] S. N. Rader, M. L. Reagan, B. Janoiko, and J. E. Johnson, "Human-in-the-Loop Operations over Time Delay: Lessons Learned," presented at the 43rd International Conference on Environmental Systems, Vail, CO, 2013.

[17] A. F. Abercromby, S. P. Chappell, H. Litaker, M. Reagan, and M. L. Gernhardt, "NASA Research and Technology Studies (RATS) 2012: Virtual Simulation and Evaluation of Human and Robotic Systems for Exploration of Near-Earth Asteroids," presented at the 43rd International Conference on Environmental Systems, Vail, CO, 2013.

[18] J. Frank, L. Spirkovska, R. McCann, L. Wang, K. Pohlkamp, and L. Morin, "Autonomous mission operations," presented at the Aerospace

Conference, 2013 IEEE, 2013, pp. 1-20.

[19] A. R. Gross, D. E. Cooke, and B. P. Hine III, "The critical role of information technology in human space exploration," AIAA Space 2000 Conference and Exposition, 2000.

[20] S. G. Love and M. L. Reagan, "Delayed Voice Communication," Acta Astronautica, 2013.

[21] H. Beyer and K. Holtzblatt, Contextual Design. San Francisco, CA: Morgan Kaufmann Publishers, 1998.

[22] K. M. Feigh, A. R. Pritchett, T. W. Denq, and J. A. Jacko, "Contextual Control Modes During an Airline Rescheduling Task," Journal of Cognitive Engineering and Decision Making, vol. 1, no. 2, pp. 169-185, Jun. 2007.
[23] S. Elo and H. Kyngäs, "The qualitative content analysis process," J Adv Nurs, vol. 62, no. 1, pp. 107-115, Apr. 2008.

[24] E. M. Jones, Ed., Apollo Lunar Surface Journal. [Online]. Available:

http://www.hq.nasa.gov/alsj/a16/a16.html.

[Accessed: 2014].

[25] G. R. Taylor, Ed., "Proceedings of the Microbial Response to Space Environment Symposium," Lyndon B Johnson Space Center, Houston, TX, NASA TM X-58103, May 1973.

[26] U. Fischer and J. Orasanu, "Cultural variability in crew discourse," 1999.

[27] J. H. Covington, "Review of Extravehicular Activity for Shuttle Program," Proceedings of the Human Factors and Ergonomics Society Annual Meeting, vol. 18, no. 5, pp. 577-584, Oct. 1974.

[28] D. S. F. Portree and R. C. Treviño, Walking to Olympus : an EVA chronology. Washington, DC : NASA History Office, Office of Policy and Plans, NASA Headquarters, 1997.

[29] J. Jairala, R. Durkin, R. Marak, A. Prince, S. Sipila, Z. Ney, S. Parazynski, and A. Thomason, "Extravehicular Activity Development and Verification Testing at NASA's Neutral Buoyancy Laboratory," presented at the 42nd International Conference on Environmental Systems, San Diego, CA, 2012.

[30] M. A. Jaramillo, B. L. Angermiller, R. M. Morency, and S. L. Rajululu, "Refinement of Optimal Work Envelope for Extra-Vehicular Activity (EVA) Suit Operations," NASA Johnson Space Center, 20080042401, Sep. 2008.

[31] B. N. Griffin, R. Howard, S. Rajulu, and D. Smitherman, "Creating a Lunar EVA Work Envelope," presented at the International Conference on Environmental Systems, Savannah, GA, 2009.

[32] J. C. Watts, D. D. Woods, J. M. Corban, E. S. Patterson, R. L. Kerr, and L. C. Hicks, "Voice loops as cooperative aids in space shuttle mission control," presented at the Proceedings of the 1996 ACM conference on Computer supported cooperative work, 1996, pp. 48-56.

[33] S. K. Moore and M. A. Gast, "21st Century extravehicular activities: Synergizing past and present training methods for future spacewalking success," Acta Astronautica, vol. 67, no. 7, pp. 739-752, Oct. 2010.

[34] A. F. Abercromby, S. P. Chappell, and M. L. Gernhardt, "Desert Rats 2011: Human And Robotic Exploration Of Near-Earth Asteroids," Acta Astronautica, no. 91, pp. 34-48, May 2013.

\section{BIOGRAPHY}

INSERT PHOTO Matthew Miller is a graduate research assistant in the Cognitive Engineering Center at the Georgia Institute of Technology. He has interned at the NASA Johnson Space Center, Charles S. Draper 
Laboratory, The Aerospace Corporation, and ATA Engineering. He received a B.S. and a M.S. in Aerospace Engineering from Georgia Institute of Technology in 2012 and 2014, respectively, and is currently pursuing his Ph.D. His research interest is in the area of decision making and decision support development in complex work domains such as time-delayed environments. He is supported by a NASA Space Technology Research Fellowship and is advised by Dr. Karen Feigh.

INSERT PHOTO Kerry McGuire Insert Bio.

INSERT PHOTO Karen Feigh Insert Bio. 
Hi Dave, Below are my responses (in red). I can't thank you enough for providing this level of feedback. I really appreciate your insight to help make this paper as informative as possible.

[1] Section 1: In Table I, I know the distances of NEOs vary quite a bit, but it would be good to have a close and far example distance for the types of missions we've been looking at. Of course, getting those numbers is easier said than done.

a. I honestly haven't found any good credible sources that have given me this sort of data. I have cited what I've found to be the most recent descriptions of an asteroid redirect mission but even they don't give distances...

[2] Section 1, $3^{\text {rd }}$ paragraph: Why use Apollo 16 EVA 4 as a case study?

a. This EVA was chosen because it was 1) the EVA was performed outside of LEO, but not on the moon, so I'm saying it loosely resembles what an asteroid redirect class mission should look like and 2) it was a relatively shorter mission so as the data analysis could be line by line on the transcript (Corrections made in Paper)

[3] Section 2, $2^{\text {nd }}$ paragraph: Are you going to include the Mission Evaluation Room (MER) engineering support also?

a. I decided that including MER would have been too much for this one conference paper. Future studies probably could and should include MER, my resources at the time were limited on MER which is also why I decided to only briefly mention that MER exists.

[4] Section 2, $4^{\text {th }}$ paragraph: Keep in mind that the crew and MCC had minimal (if any) training, which contributed to the breakdown of comm over the 5 and 10 min delays.

a. Yes, after talking with some other people who mentioned that as well, I will reword this section, noting that point. PUT IN DISCUSSION SECTION

[5] Section 2, $5^{\text {th }}$ paragraph: RATS 2012 showed the importance of a dedicated IV crewmember, but that's not a new lesson learned. We either have a dedicated onboard IV (usually during shuttle flights) or a dedicated ground IV for current operations. RATS 2012 showed us that we need to continue with having an IV in a real-time loop, which means having that IV with the crew and not on in MCC.

a. Thank you for that clarification, I'll reword my phrasing here. (Corrections made in Paper)

[6] Section 2, $6^{\text {th }}$ paragraph: You did point out that AMO didn't do EVAs, but you'll need to be careful about comparing anything they did in an IVA environment with how things might be done EVA. Not to say that their worked can't be used, but it'll require some "translation" to put it into an operational EVA environment.

a. Thank you for this perspective. I'd actually like to discuss this point further offline with you to get your insight as to what those "translation" points might be. The primary purpose of including AMO is because this is the only study to date that has attempted to examine the impact of technological support for time-delayed ops (granted it wasn’t related to EVA) (Corrections made in Paper)

[7] Section 2, $7^{\text {th }}$ paragraph: Concur with everything said, but keep in mind that the analog missions influenced a lot of the findings that lead to these identified challenges, and there was a lack of training with the crew and MCC for those missions due to time and budget constraints.

a. Point taken, I'll include some rephrasing to explain this point. PUT IN DISCUSSION SECTION

[8] Section 3, $1^{\text {st }}$ paragraph: Can you explain more why you're using a current EVA work domain but looking at communication from Apollo 16, and how those relate?

a. I'm looking at current work domain because 1) This sort of examination of the EVA work domain isn't present in the academic literature and for the purposes of my thesis (and my own personal understanding) I need to know how EVAs are currently done today. I can then build off of this present day work domain to start talking about future deep-space EVA work domains how things will change operationally to account for the time-delay. As for the Apollo 16 EVA 4, this is one of the only EVAs that has been conducted outside of LEO making this one of the one precedents we have for future EVAs beyond LEO. It was also one of the only data sources I had at the start of this work so I was basically working with what I had at the time. (Corrections made in Paper)

[9] Section 3, $5^{\text {th }}$ paragraph: Was Apollo 16 EVA 4 used because it was a deep space EVA?

a. Yes, I'll try to make this point clear earlier in the paper. (Corrections made in Paper) 
[10] Section $4,2^{\text {nd }}$ paragraph: It might be worth specifically noting that crew do receive some training on tasks that may be performed in unscheduled and contingency EVAs.

a. Thank you for that clarification, I'll add this to the paper (Corrections made in Paper)

[11] Section 4, Figure 2: Is the timeline margin equivalent to the padding (\% time over the NBL time to allow for on orbit differences) we put into EVAs?

a. I hadn't specifically thought about that sort of padding (to account for NBL differences from on orbit), but yes that would also fit inside that discussion. I was basically trying to say that you can possibly get ahead of schedule in an EVA timeline. I'll add this discussion point. (Corrections made in Paper)

[12] Section 4, Figure 2: What does the "Crib Sheet Region" indicate? It's possible to utilize the cribsheet anytime through the EVA.

a. For this region, I am trying to say that for a given point in the timeline, there exists a tool (i.e. cribsheet) that can assist you in completing tasks that may not have been nominal. But the crib sheet can only help you for so many off-nominal tasks. As I understand it, the cribsheet is built to be as exhaustive as possible to account for any of the foreseen issues that may arise. But my point is that we can only foresee so many issues arising. (Corrections made in Paper)

[13] Section $4,7^{\text {th }}$ paragraph: Chatter on the MCC loops can actually be rather busy, even during nominal operations.

a. Thanks for that point. I'll try and clarify this statement (Corrections made in Paper)

[14] Section 4, $8^{\text {th }}$ paragraph (Off-Nominal Operations): I'm not sure it's true that the comm increases depending on the severity of the situation. Sometimes the chatter can be rather minimal during those times as folks are extra vigilant to listen to the crew. Chatter increases with the number of failures and with the timing.

a. Thanks for that point. I'll try and clarify this statement (Corrections made in Paper)

[15] Section 5, $8^{\text {th }}$ paragraph: The EVA FCR controls the development of the checklists and procedures.

a. Thank you for this insight, I've added this point to the paper. (Corrections made in Paper)

[16] Section 5, $10^{\text {th }}$ paragraph: EVA Task also tracks the ahead/behind time based on the planned timeline.

a. Thank you for this insight, I've added this point to the paper. (Corrections made in Paper)

[17] Section 5, $11^{\text {th }}$ paragraph: You may want to stress that the EMU position is the primary person tracking the crew's limited consumables (O2, power, $\mathrm{CO} 2$ scrubbing). That's going to be a critical difference with the Exploration missions due to the comm delay.

a. Thank you for emphasizing this point, I'll clarify this in the paper. I was thinking this was the case but again, my resources couldn't tell me for sure this was the case. (Corrections made in Paper)

[18] Section 5, $13^{\text {th }}$ paragraph: BME is actually one of the FCR positions, they just don't work for the operations directorate.

a. Thank you for emphasizing this point, I'll clarify this in the paper. (Corrections made in Paper)

[19] Section 5, EVA Information Flow Model, $3^{\text {rd }}$ paragraph: During real-time EVA ops, we primarily use the voice loops, flight notes, JEDI messages, Anomaly database, OSTPV (electronic crew timeline).

a. Thank you for clarifying, I simply omitted BME from the discussion since I didn't think it really contributed to the conversation (Corrections made in Paper)

[20] Section 5, EVA Information Flow Model, $4^{\text {th }}$ paragraph: There is a lot of "airwave" conversations between the flight director, Ground IV, and EVA FCR that is not over the comm loops.

a. I've been looking into this chatter more recently and I need to add this as well. Thank you for emphasizing this point. I'd also like to talk more with you offline about what is actually being said in these conversations. (Corrections made in Paper)

[21] Section 5, EVA Information Flow Model, $6^{\text {th }}$ paragraph: We rely on voice and video downlink, and we lose the video more than the audio, which does affect our situational awareness.

a. Your statement aligns with what my sources also said. I'll clarify this point in the paper. (Corrections made in Paper)

[22] Section 5, EVA Information Flow Model, $8^{\text {th }}$ paragraph: The EVA FCR is concerned about the big picture of the EVA with respect to both the timeline and the EMU/Airlock, as well as how those affect or are affected by the vehicle systems. The FCR has to keep the Task and EMU/Airlock coordinated in order to execute the EVA - for instance, the FCR determines whether or not to do a particular task based on 
timeline input from Task and consumable input from EMU. The FCR also filters all of the data being received from the three MPSR positions.

a. Thank you for providing this additional insight, I'll make the appropriate modifications in the paper. (Corrections made in Paper)

[23] Section 5, EVA Information Flow Model, $9^{\text {th }}$ paragraph: Communication in the flight control room is also complicated by the need to not step on (talk over) other operators or the crew. A lot of information must be relayed between operators in succinct a manner as possible.

a. This is another great discussion point I can include in the paper. Thank you (Corrections made in Paper)

[24] Section 6: Do you have any plans to extend the analysis to a more recent EVA?

a. Yes, I have the Air-to-Ground EVA audio/video for EVA 26 (in progress), and then the EVA 15, 16, 17 series that I plan on analyzing. I'm also pulling the MCC loops for EVA 26 to better understand the chatter that goes on. I would actually like to discuss with you any additional metrics or points of analysis you think would be worth extracting from these videos.

[25] Section 6, $2^{\text {nd }}$ paragraph: The IV crewmembers were fully suited, correct? That might be worth noting as a difference between this EVA and Shuttle/ISS EVAs.

a. That's a great point, you are correct, all three crew were fully suited and the entire cabin was depressed. This is also possibly analogous to what operations in Orion might be like. PUT IN DISCUSSION SECTION

[26] Section 6, Figure 5: I'm surprised CAPCOM talked so little during the EVA. It might be good to see how that compares to ISS EVAs. And also interesting to see how that compares to a delayed comm EVA from NEEMO.

a. My thoughts exactly, I would love to see that comparison too. Once I get EVA 26 analyzed, I'd love to get my hands on NEEMO audio transcripts to make that comparison. Discussed in Future work

[27] Section 6, Table IV: Did the ground provide much direction to the crew, or were they basically conducting the EVA almost autonomously.

a. I think this point is discussed a little later in the paper, but maybe I should make the point more clear. The crew was fairly autonomous. Ground really didn’t direct anything during the EVA. The crew really relied on their flight notes (cribsheets) for all activities. PUT IN DISCUSSION SECTION

[28] Section 6: Was the ground tracking any consumable status for the crew? Since the EVA was so short, they may not have been.

a. I couldn't really tell if that was the case. There really was no mention of consumables throughout the entire transcript that I read.

[29] Section 6, $6^{\text {th }}$ paragraph: The MEED experiment phase might be a good comparison for an Exploration science EVA as a more complicated task.

a. That's a good point to make. I'll clarify this in the paper. PUT IN DISCUSSION SECTION

[30] Section 6: I'm assuming not, but there wasn't a video camera showing any of the EVA, was there? That might change the voice comm a bit. We commonly see things during ISS EVAs so that we don't have to talk to the crew.

a. This is also a good point to make, they did spend time setting up a camera but I'm not entirely sure how much MCC relied on that video/image feed. My impression was that they didn't (there was quite a few instances of them having to readjust to ensure a good link with ground and there wasn't really any evidence that MCC was leveraging the video all that much) PUT IN DISCUSSION SECTION

[31] Section 7, $2^{\text {nd }}$ paragraph: One of the things affecting comm during DRATS (and NEEMO) was the lack of specific crew training and flight control team training. We'll more than likely end up with an onboard IV during Exploration missions, but the comm will be different with more dedicated training.

a. So this point is exactly what I want my Thesis to contribute to. Understanding how that comm will be different in deep-space EVAs is one of the big-ticket items I'd like to address. I'm currently drafting my thesis proposal, which I'd love to discuss with you in further detail so we can make 
sure that I'm working towards this goal. I know you've been thinking about this problem a lot and I would appreciate any insight you may have. PUT IN DISCUSSION SECTION

[32] Section $7,3^{\text {rd }}$ paragraph: Training and planning will also be key to alleviating some of the time delay challenges.

a. Yes, I agree. I'll clarify this statement in the paper. (Corrections made in Paper)

[33] Section 7, $4^{\text {th }}$ paragraph: AMO might have seen some comm breakdown due to the way they ran things, but we showed in RATS and NEEMO that you can work around the time delay.

a. This is another great point that I'll clarify in the paper. I'd also like to discuss with you in more detail about these work arounds that were found in RATS and NEEMO. (Corrections made in Paper)

[34] Section 7, $4^{\text {th }}$ paragraph: Exploration missions will have scientists also making queries and requests of the EVA crew that will be very different from what we've seen with shuttle or station.

a. True, I'll add this distinction to the paper as well. (Corrections made in Paper)

[35] Conclusions, $2^{\text {nd }}$ paragraph: In current EVAs, MCC also tracks the consumables, which is key function in EVAs.

a. Yes, this is also another valuable insight that is worth mentioning. (Corrections made in Paper) 